\title{
Factors Associated with Operation Time of Laparoscopic Gastric Wedge Resection for Gastric Subepithelial Tumors
}

\author{
Dong-Hyeon Oh, M.D. ${ }^{1}$, Yong-Eun Park, M.D. ${ }^{1}$, Sang-Woon Kim, M.D. ${ }^{1,2}$, Jung-Min Bae, M.D. ${ }^{1,2}$ \\ ${ }^{1}$ Department of Surgery, Yeungnam University Medical Center, ${ }^{2} Y e u n g n a m$ University College of Medicine, Daegu, Korea
}

\begin{abstract}
Purpose: Gastric subepithelial tumor (GST) is a disease entity that includes all gastric subepithelial lesions. The oncologically safe surgical technique is complete resection with adequate resection margins. Most of the studies about laparoscopic gastric wedge rsection (LGWR) in GST focus on oncologic curability or surgical effectiveness. However, studies on the factors associated with the operation time are rare. Therefore, this study was conducted to analyze and compare the factors associated with the operation time of LGWR.
\end{abstract}

Methods: From 2010 to 2019, 145 consecutive patients undergoing LGWR were reviewed retrospectively. Clinical characteristics of GST and operation time were analyzed and compared.

Results: A total of 145 patients was enrolled and reviewed. There were 59 males (40.7\%) and 86 females (59.3\%) with a mean age of 53.6 years and mean body mass index (BMI) of $23.9 \mathrm{~kg} / \mathrm{m}^{2}$. Mean tumor size was $2.9 \mathrm{~cm}$ and mean operation time was 66.0 minutes. In statistically, the mean operation time showed significant association with tumor size, BMI, longitudinal tumor location and tumor location between lesser and greater curvature. In multivariate analysis, tumor size, BMI and longitudinal classification of tumor location are statistically significant.

Conclusion: A shorter operation time is expected when there is a small tumor, low BMI and mid portion of the stomach GST. Preoperative evaluation for tumor size and body weight is important. In patients with large GST, obesity and both end stomach GST, we think that pre-operative preparation for long operation time should be considered.

Keywords: Stomach neoplasms, Laparoscopy, Gastrectomy

This is an Open Access article distributed under the terms of the Creative Commons Attribution Non-Commercial License (http:// creativecommons.org/licenses/by-nc/4.0/) which permits unrestricted non-commercial use, distribution, and reproduction in any medium, provided the original work is properly cited.

\author{
Received June 3, 2020 \\ Revised August 12, 2020 \\ Accepted August 20, 2020 \\ Corresponding author \\ Jung-Min Bae \\ Department of Surgery, Yeungnam \\ University Medical Center, \\ Yeungnam University College of \\ Medicine, 170 Hyeonchung-ro, Nam- \\ gu, Daegu 42415, Korea \\ Tel: +82-53-620-3580 \\ Fax: +82-53-624-1213 \\ E-mail: netetern@naver.com \\ ORCID: \\ https://orcid.org/0000-0003-0923-763X
}

\section{INTRODUCTION}

Gastric subepithelial tumor (GST) is a disease entity that includes all gastric subepithelial lesions, such as gastro-intestinal stromal tumor (GIST), lipoma, leiomyoma, schwannoma, and ectopic pancreas. Most GSTs are asymptomatic and identified during incidental endoscopic examination.

An accurate pathologic diagnosis on endoscopic biopsy is difficult. Therefore, accurate pathologic diagnosis is made by operative resection. The oncologically safe surgical technique is complete resection with adequate resection margins, because most of the benign GSTs as well as GIST have no lymph node metastasis. The current guidelines recommend that laparoscopic resection is the preferred treatment modality for GIST $(2 \mathrm{~cm} \sim 5$ $\mathrm{cm}$ ). ${ }^{1}$ Therefore, laparoscopic gastric wedge resection (LGWR) is popular surgical manner in most of GSTs.

Most of the studies about LGWR in GST focus on oncologic curability or surgical effectiveness. However, studies on the factors associated with the operation time are rare. The shorter operation time is related on lesser morbidity. 
Therefore, this study was conducted to analyze and compare the factors associated with the operation time of LGWR.

\section{MATERIALS AND METHODS}

From January 2010 to May 2019, 145 consecutive patients who underwent LGWR were retrospectively reviewed. All LGWR procedures were performed by specialized gastro-intestinal laparoscopic surgeons. The pre-operative definite diagnosis in all patients were unclear between GIST and other benign tumors.

Four or five port maneuvers were used. One $12 \mathrm{~mm}$ trocar for a laparoscope was inserted at the umbilical site. Other three or four ports were inserted in the lateral upper abdominal area.

All patients had a single tumor lesion with no metastasis on preoperative computed tomography. The patients with history of previous abdominal operation were excluded. Clinical characteristics were collected from medical records. Factors investigated included age, sex, body mass index (BMI) tumor size, tumor location, tumor growth pattern, pathologic result, and operation time. Tumor size was defined as the largest diameter of the tumor. Tumor location was defined as the anatomical system according to the gastric cancer reporting guidelines. ${ }^{2}$

Clinical characteristics of GST and operation time were analyzed and compared. We statistically analyzed the differences in the factors.

\section{Statistical analysis}

Analysis of demographic and clinical characteristics was performed using descriptive statistics. Comparison of the operation time between variables was performed using the Student t-test and the one way ANOVA test. Multivariate analysis was performed multiple regression analysis. All tests were two-sided and $p$ values less than 0.05 were considered statistically significant. IBM SPSS Statistics ver. 12.0 (IBM Co. Armonk, NY, USA) was used for analysis.

This study was approved by the Institutional Review Board of Yeungnam University Medical Center (IRB No. 2019-12-008-001). The requirement for informed consent was waived because of the retrospective nature of the study. Medical records and clinical information were anonymized prior to the analysis.

\section{RESULTS}

A total of 145 patients were enrolled and reviewed. Patient demographics and clinicopathologic characteristics are summarized in Table 1. There were 59 males (40.7\%) and 86 females (59.3\%) with a mean age of 53.6 years and mean BMI of $23.9 \mathrm{~kg} / \mathrm{m}^{2}$. The mean tumor size was $2.9 \mathrm{~cm}$, and the mean operation time was 66.0 minutes.
Table 1. Demographic and clinicopathologic characteristics

\begin{tabular}{|c|c|c|}
\hline \multicolumn{2}{|c|}{ Variables } & \multirow{2}{*}{$\begin{array}{c}\mathrm{N}(\%) \\
43(29.6)\end{array}$} \\
\hline Tumor size $(\mathrm{cm})$ & $<2$ & \\
\hline & $2 \leq,<5$ & $85(58.6)$ \\
\hline & $5 \leq$ & $17(11.8)$ \\
\hline \multirow[t]{2}{*}{ Sex } & Male & $59(40.7)$ \\
\hline & Female & $86(59.3)$ \\
\hline \multirow[t]{7}{*}{ Age } & $<20$ & $2(1.4)$ \\
\hline & $20 \leq,<30$ & $6(4.1)$ \\
\hline & $30 \leq,<40$ & $7(4.8)$ \\
\hline & $40 \leq,<50$ & $34(23.4)$ \\
\hline & $50 \leq,<60$ & $46(31.7)$ \\
\hline & $60 \leq,<70$ & $37(25.5)$ \\
\hline & $70 \leq$ & $13(9.0)$ \\
\hline \multirow[t]{3}{*}{$\mathrm{BMI}\left(\mathrm{kg} / \mathrm{m}^{2}\right)$} & $<25$ & 98 (67.6) \\
\hline & $25 \leq,<30$ & $44(30.3)$ \\
\hline & $30 \leq$ & $3(2.0)$ \\
\hline \multirow[t]{5}{*}{ Pathology } & GIST & 89 (61.4) \\
\hline & Ectopic pancreas & $18(12.4)$ \\
\hline & Schwannoma & $17(11.8)$ \\
\hline & Leiomyoma & $12(8.3)$ \\
\hline & others & $9(6.2)$ \\
\hline \multirow{7}{*}{$\begin{array}{l}\text { Tumor location } \\
\text { (longitudinal) }\end{array}$} & Cardia & $12(8.3)$ \\
\hline & Fundus & $41(28.3)$ \\
\hline & Proximal body & $32(22.0)$ \\
\hline & Mid body & $13(9.0)$ \\
\hline & Distal body & 23 (15.9) \\
\hline & Antrum & 31 (21.4) \\
\hline & Distal antrum & $3(2.0)$ \\
\hline \multirow{3}{*}{$\begin{array}{l}\text { Tumor location } \\
\text { (ant. vs post) }\end{array}$} & Ant. wall & $57(39.3)$ \\
\hline & Post. wall & $80(55.1)$ \\
\hline & Ambiguous & $8(5.5)$ \\
\hline \multirow{3}{*}{$\begin{array}{l}\text { Tumor location } \\
\text { (Greater vs Lesser) }\end{array}$} & Greater curvature & 53 (36.5) \\
\hline & Lesser curvature & $52(35.9)$ \\
\hline & Ambiguous & $40(27.6)$ \\
\hline \multirow[t]{4}{*}{ Operation time (hour) } & $<1$ & $90(62.0)$ \\
\hline & $1 \leq,<2$ & $41(28.3)$ \\
\hline & $2 \leq,<3$ & $13(9.0)$ \\
\hline & $3 \leq$ & $1(0.7)$ \\
\hline \multirow[t]{3}{*}{ Growth pattern } & Endophytic & $76(52.4)$ \\
\hline & Exophytic & $65(44.8)$ \\
\hline & Ambiguous & $4(2.7)$ \\
\hline
\end{tabular}

$\mathrm{BMI}=$ body mass index; GIST = gastro-intestinal stromal tumor. 
Table 2. Comparison of the factors associated with operation time

\begin{tabular}{|c|c|c|c|}
\hline & & $\begin{array}{l}\text { Mean operation } \\
\text { time (min) }\end{array}$ & $p$ value \\
\hline \multirow[t]{2}{*}{ Sex } & Male & 69.1 & 0.405 \\
\hline & Female & 63.9 & \\
\hline \multirow[t]{3}{*}{ Tumor size } & $<2$ & 50.2 & 0.011 \\
\hline & $2 \leq,<5$ & 67.1 & \\
\hline & $5 \leq$ & 83.5 & \\
\hline \multirow[t]{3}{*}{$\mathrm{BMI}\left(\mathrm{kg} / \mathrm{m}^{2}\right)$} & $<25$ & 61.3 & 0.028 \\
\hline & $25 \leq,<30$ & 75.5 & \\
\hline & $30 \leq$ & 78.3 & \\
\hline \multirow{2}{*}{$\begin{array}{l}\text { Tumor location } \\
\text { (Iongitudinal) }\end{array}$} & Both end & 86.5 & 0.017 \\
\hline & Mid portion & 63.4 & \\
\hline \multirow{2}{*}{$\begin{array}{l}\text { Tumor location } \\
\text { (circumference, } \\
\text { ant. vs post) }\end{array}$} & Ant. wall & 57.8 & 0.073 \\
\hline & Post. wall & 68.5 & \\
\hline \multirow{2}{*}{$\begin{array}{l}\text { Tumor location } \\
\text { (circumference, } \\
\text { Greater. vs Lesser) }\end{array}$} & Greater curvature & 58.0 & 0.012 \\
\hline & Lesser curvature & 75.1 & \\
\hline \multirow[t]{2}{*}{ Growth pattern } & Endophytic & 68.6 & 0.229 \\
\hline & Exophytic & 61.3 & \\
\hline
\end{tabular}

There were 89 GIST cases (61.4\%), 18 ectopic pancreas cases (12.4\%), 17 schwannoma cases (11.8\%) and 12 leiomyomas cases (8.3\%).

The comparative results between the operation time and various factors are summarized in Table 2. Statistically, the mean operation time showed a significant association with tumor size, BMI, longitudinal tumor location, and tumor location between the lesser and greater curvatures (Table 2).

\section{DISCUSSION}

Laparoscopic surgery has many advantages compared to open surgery. For GST, accurate pathologic diagnosis is difficult through preoperative endoscopic biopsy. Therefore, surgical resection is the treatment as well as the pathologic diagnostic tool. For GST, local resection with negative margins is the treatment of choice because lymph node metastasis is rare in GST. Traditionally, open gastric resection is commonly performed for treatment of GST. ${ }^{3}$

In 1992, laparoscopic resection of gastric benign stromal tumor was reported for the first time. ${ }^{4}$ Later, LGWR provided a superior outcome compared to open wedge resection. ${ }^{5,6}$ Currently, laparoscopic resection including wedge resection or partial gastrectomy is the standard approach for resection of GST.

Benign GSTs, including leiomyoma, ectopic pancreas, and schwannoma, are oncologically safe in local resection. Although GIST as the major type of GST has malignant potential, the primary treatment is local resection because lymph node metastasis is rare in GIST. Current guidelines recommend that laparoscopic resection is the preferred treatment modality for GIST $(2 \mathrm{~cm} \sim 5$ $\mathrm{cm}){ }^{1}$ In a recent study, for larger GISTs over $5 \mathrm{~cm}$ in size, the surgical and oncologic outcomes of LGWR for GIST were safe and feasible compared to open surgery. ${ }^{8,9}$

Further, 50 55\% of GSTs were located in the upper stomach in our study. This result was similar to that of a previous Korean study. ${ }^{3}$ The mean operation time in our study was 66 minutes. In several studies, the mean operation time varied. ${ }^{6,10-12}$ This variation in the mean operation time is due to different study designs, different surgical skills, and different tumor characteristics. According to sex classification, the mean operation time was not significantly different in our study. The same result was obtained in a previously reported study. ${ }^{10}$

The mean operation time according to tumor size classification was significantly different in our study. However, some authors reported that there was no significant difference according to the tumor size. ${ }^{10}$ For large GISTs (size $>5 \mathrm{~cm}$ ) except benign GSTs, laparoscopic approach is not recommended in recent research. ${ }^{13-15}$ However, with favorable case selection and expert gastro-intestinal laparoscopic surgeons, several authors have demonstrated that LGWR is feasible and oncologically safe for larger GISTs. ${ }^{16}$ In large GSTs, not only the simple tumor size but also the growth pattern is important when laparoscopic resection is considered. ${ }^{17}$

However, there is no consensus on the international standardization of growth pattern classification. The exophytic type is called as exogenous or extraluminal pattern. ${ }^{12,17}$ The difference in the dumbbell and exophytic pattern is ambiguous. However, in large GSTs $(>5 \mathrm{~cm}$ ), the exophytic lesion is more likely than the intraluminal or intragastric type. With respect to GSTs $>5$ $\mathrm{cm}, 17$ patients were enrolled in this study; 11 patients had GISTs and 7 patients had benign GSTs. Further, 11 patients had GISTs, 10 patients had a tumor size of $5 \sim 6 \mathrm{~cm}$, and only 1 patient had a tumor size of $10 \mathrm{~cm}$. In the $10 \mathrm{~cm}$ GISTs, the growth pattern was exophytic. Therefore, LGWR was performed using a laparoscopic linear stapler without tumor rupture or spillage. Therefore, we think that LGWR may be considered if an exophytic growth pattern on preoperative evaluation is expected in large GSTs. However, there was no significant difference in the operation time according to the growth pattern in our study and a previously reported study. ${ }^{10}$

Generally, in obese patients, the operation time is longer than that in lean patients for general surgery or laparoscopic gastrectomy. ${ }^{18,19}$ The degree of obesity is frequently classified by BMI. 
Table 3. Multivariate analysis according to multiple regression analysis

\begin{tabular}{lc}
\hline \multicolumn{1}{c}{ Variables } & $p$ value \\
\hline Tumor size & 0.012 \\
BMl & 0.042 \\
Tumor location (longitudinal) & 0.024 \\
Tumor location (circumference, greater vs lesser) & 0.275 \\
\hline
\end{tabular}

The BMI classification has been divided by $25 \mathrm{~kg} / \mathrm{m}^{2}$ above or below in a previously reported study. ${ }^{10}$ Recently, the BMI classification has been declared. ${ }^{20}$ This classification system has been adopted in our study. In our study, there was a significant difference in the operation time according to the BMI classification.

The GST tumor location has two characteristics in longitudinal and circumferential locations. In the LGWR study of GSTs or GISTs, the tumor location classification system is not uniform. Therefore, tumor location classification in a previously reported study varied. ${ }^{10-12,17,21}$ However, in gastric cancer, tumor location description standardization was performed and widely used. ${ }^{2}$ This standardization is needed for an effective study, conversation, and cooperative research between each physician and each institution. Therefore, we think that international description standardization of GSTs is needed for effective international research.

The longitudinal location is called vertical or axial location in another study. ${ }^{5,10}$ The circumferential location is called horizontal or cross-sectional location in another study. ${ }^{2,5}$ In some study, the cross-sectional location was divided to the anterior-greater group and the posterior-lesser group. ${ }^{11}$ Because of this discrepancy, a direct comparison is difficult due to different classification systems but, in many studies, LGWR of GST located in the anterior wall and greater curvature is easier and more favorable. ${ }^{22,23}$ However, in our study, there was no statistical difference between the anterior and posterior wall. According to the tumor location classification in our study, the mean operation time was significantly different in the longitudinal location and the circumferential (greater versus lesser curvature) location. This result was due to the difference in the laparoscopic tumor approach or resection difficulty.

Generally, when GST is close to the pylorus or the esophagogastric junction, LGWR may cause stenosis in the pylorus or the esophago-gastric junction. ${ }^{11,12}$ GSTs at both ends of the stomach may require expert level laparoscopic surgical skills and it is a time-consuming procedure. In our cases, GST was absent in the esophago-gastric junction or the pyloric ring. In 3 patients, GST was located in the distal antrum and these tumors were located near the pyloric ring. In our study, we classified the longitudinal location to both end and mid portion of the stomach. According to this classification, there was a statistical difference in the mean operation time.

In multivariate analysis, tumor size, BMI and longitudinal classification of tumor location are statistically significant (Table 3).

This study has some limitations. Data were retrospectively reviewed. The study was performed at a single center. The patients in the study underwent LGWR by several laparoscopic gastrointestinal surgeons. The endoscopic guidance of a small tumor suture procedure of resected opening or other various different sub-procedure were not considered in the study.

In conclusion, on the basis of our results, a shorter operation time is expected when there is a small tumor, low BMI and mid portion tumor of the stomach. Although it is difficult to generalize according to this result, pre-operative evaluation for tumor size, tumor location and BMI is important. In patients with large GST, obesity and both end stomach GST, we think that pre-operative preparation for long operation time should be considered. Additionally, for an effective study in inter-researcher or interinstitution, standardization of the description of GST is needed.

\section{ORCID}

Dong-Hyeon Oh, https://orcid.org/0000-0002-4753-4582

Yong-Eun Park, https://orcid.org/0000-0001-6882-2973

Sang-Woon Kim, https://orcid.org/0000-0003-1522-1685

Jung-Min Bae, https://orcid.org/0000-0003-0923-763X

\section{AUTHORS' CONTRIBUTIONS}

Jung-Min Bae is the surgeon who performed the surgery, conceptualization, participated in the description of manuscript and correction and revision of manuscript. Dong-Hyeon Oh is the doctor who performed data acquisition and participated in the description of manuscript. Yong-Eun Park and Sang-Woon Kim is the surgeon who performed the surgery. All authors have read and approved the manuscript.

\section{CONFLICT OF INTEREST}

None.

\section{FUNDING}

None.

\section{ACKNOWLEDGMENTS}

None. 


\section{REFERENCES}

1) Demetri GD, von Mehren M, Antonescu CR, et al. NCCN Task Force report: update on the management of patients with gastrointestinal stromal tumors. J Natl Compr Canc Netw 2010;8 Suppl 2:S1-41; quiz S42-44.

2) Kim WH, Park CK, Kim YB, et al. A Standardized Pathology Report for Gastric Cancer. Korean J Pathol 2005;39:106-113.

3) The Information Committee of the Korean Gastric Cancer Association. 2005 2006 Nationwide Gastric Submucosal Tumor Report in Korea. J Korean Gastric Cancer Assoc 2008;8:104-109.

4) Lukaszczyk JJ, Preletz RJ, Jr. Laparoscopic resection of benign stromal tumor of the stomach. J Laparoendosc Surg 1992;2:331-334.

5) Shimizu S, Noshiro H, Nagai E, Uchiyama A, Mizumoto K, Tanaka M. Laparoscopic wedge resection of gastric submucosal tumors. Dig Surg 2002;19:169-173.

6) Bae JM, Kim SW, Kim SW, Song SK. Comparison of Clinical Characteristics between Open and Laparoscopic Surgery Groups in Gastric Gastrointestinal Stromal Tumor Patients. J Korean Surg Soc 2010;79: 455-459.

7) Chang YS. Factors Affecting the Length of Hospitalization after Laparoscopic Resection of Gastric Subepithelial Tumor. J Minim Invasive Surg 2019;22:89-90.

8) Yang Z, Li P, Hu Y. Laparoscopic versus open wedge resection for gastrointestinal stromal tumors of the stomach: a meta-analysis. Wideochir Inne Tech Maloinwazyjne 2019;14:149-159.

9) Stanek M, Pisarska M, Rzepa A, Radkowiak D, Major P, Budzyński A. Laparoscopic treatment of large gastrointestinal stromal tumors (> 5 cm). Wideochir Inne Tech Maloinwazyjne 2019;14:170-175.

10) Choi KS, Jeong GA, Cho GS, et al. Factors Associated with Operation Time of Laparoscopic Wedge Resection for Gastric Submucosal Tumors. J Minim Invasive Surg 2009;12:14-20.

11) Lee HH, Hur H, Jung H, Park CH, Jeon HM, Song KY. Laparoscopic wedge resection for gastric submucosal tumors: a size-location matched case-control study. J Am Coll Surg 2011;212:195-199.

12) Zhang H, Huang $X, Q u$ C, Bian C, Xue H. Comparison between laparoscopic and endoscopic resections for gastric submucosal tumors. Saudi J Gastroenterol 2019;25:245-250.
13) Li J, Ye Y, Wang J, et al. Chinese consensus guidelines for diagnosis and management of gastrointestinal stromal tumor. Chin J Cancer Res 2017;29:281-293.

14) Yin $X$, Yin $Y$, Chen H, et al. Comparison Analysis of Three Different Types of Minimally Invasive Procedures for Gastrointestinal Stromal Tumors $\leq 5 \mathrm{~cm}$. J Laparoendosc Adv Surg Tech A 2018;28:58-64.

15) Lin J, Huang $C$, Zheng $C$, et al. Laparoscopic versus open gastric resection for larger than $5 \mathrm{~cm}$ primary gastric gastrointestinal stromal tumors (GIST): a size-matched comparison. Surg Endosc 2014;28: 2577-2583.

16) Takahashi $T$, Nakajima K, Miyazaki $Y$, et al. Surgical strategy for the gastric gastrointestinal stromal tumors (GISTs) larger than $5 \mathrm{~cm}$ : laparoscopic surgery is feasible, safe, and oncologically acceptable. Surg Laparosc Endosc Percutan Tech 2015;25:114-118.

17) Cao F, Li A, Li J, Fang YU, Li F. Feasibility and safety of laparoscopic resection for gastric GISTs larger than $5 \mathrm{~cm}$ : Results from a prospective study. Oncol Lett 2015;10:2081-2086.

18) Tjeertes EK, Hoeks SE, Beks SB, Valentijn TM, Hoofwijk AG, Stolker $\mathrm{RJ}$. Obesity--a risk factor for postoperative complications in general surgery? BMC Anesthesiol 2015;15:112.

19) Tae CW, Ryu SW, Kim IH, Sohn SS, Son YG. Comparative Analysis of before and after the Learning Curve and according to Obesity for Performing Laparoscopic Distal Gastrectomy in Gastric Cancer Patients. J Korean Surg Soc 2008;75:20-26.

20) Guideline Committee for Metabolic and Bariatric Surgery - Korean Society for Metabolic and Bariatric Surgery, Korean Society for Metabolic and Bariatric Surgery. 2018 Korean Society for Metabolic and Bariatric Surgery Guidelines. J Metab Bariatr Surg 2018;7:1-21.

21) Lee SJ, Min SH, Park KB, et al. Laparoscopic Treatment of Gastric Subepithelial Tumor: Finding Ways to Manage with Shorter Hospitalization Days. J Minim Invasive Surg 2019;22:106-112.

22) Goh BK, Goh YC, Eng AK, et al. Outcome after laparoscopic versus open wedge resection for suspected gastric gastrointestinal stromal tumors: A matched-pair case-control study. Eur J Surg Oncol 2015;41: 905-910.

23) Bischof DA, Kim Y, Dodson R, et al. Open versus minimally invasive resection of gastric GIST: a multi-institutional analysis of short- and long-term outcomes. Ann Surg Oncol 2014;21:2941-2948. 